\title{
Food Properties that Influence Neuromuscular Activity During Human Mastication
}

\author{
K.R. Agrawal ${ }^{1 *}$, P.W. Lucas ${ }^{1}$, I.C. Bruce ${ }^{2}$, and J.F. Prinz ${ }^{1}$ \\ ${ }^{1}$ Department of Anatomy and ${ }^{2}$ Department of Physiology, University of Hong Kong, 5 Sassoon Road, Hong Kong SAR, PR China; *to whom \\ offprint requests should be addressed
}

\begin{abstract}
The rate of breakdown of food in mastication depends on the ratio of two mechanical properties of the food-the toughness and modulus of elasticity (Agrawal et al., 1997) - a result which can be predicted by an analysis of the energetics of fracture. The work input to produce food fragmentation is provided by the masticatory muscles, the activity levels of which depend on sensory feedback from the mouth. Here, we test the hypothesis that the activity of a representative of this musculature is modulated by the above combination of food properties. The surface electrical activity (EMG) of the anterior temporalis muscles of ten human subjects was recorded while subjects chewed standardized volumes of 15 food types. The integrated EMG in these muscles was highly significantly related to the square root of the ratio of the above two food properties. Significant correlations were found between this food property index and integrated EMG, both when data for all chews and all subjects were lumped together $(r=-0.86$; $p<0.0001)$ and when correlation coefficients between the index and EMG were plotted for each chew made by each subject. Except for two subjects in the first chew, these coefficients reached and maintained highly significant levels throughout the masticatory sequence. Thus, a clear relationship between the electrical activity of a jaw-closing muscle and the mechanical properties of food has been found for the first time.
\end{abstract}

Key words: mastication, food breakdown, mechanical properties of foods, surface electromyography, temporalis muscle.

\section{Introduction}

Mastication, the breakdown of solid food particles in the mouth, is a cyclical activity controlled by a "pattern generator" located inside the central nervous system (Lund, 1976; Luschei and Goldberg, 1981; Hiiemae and Crompton, 1985). It is a difficult process to observe because of masking by the cheeks. In addition, the substrate (food), on which the teeth act, changes from chew to chew, and when there is more than one food particle in the mouth, there is always a random element to the position and orientation of these particles (Lucas and Luke, 1983). Every time the teeth bite, food particles break into fragments, and so the range of particle sizes continually changes. Consequently, it is not possible to arrange a masticatory sequence (a series of chewing cycles) that acts on a stable and even substrate. This introduces an inevitable stochastic element to mastication. Jaw movements in mastication seem to reflect this change in the food substrate. Viewed from the front, mandibular trajectories during a series of chewing cycles in a mammal are never identical (see Luschei and Goldberg, 1981). This must reflect sensory feedback from the mouth that is used to modulating jaw muscle activity continuously, thus producing the variable jaw movements seen in any masticatory sequence (Luschei and Goldberg, 1981; Lund and Widmer, 1989).

In mammals, the late-closing phase of a chewing cycle is a period when food particles are being fractured and involves slow movement (Hiiemae and Crompton, 1985; Hiiemae et al., 1995). Two basic classes of food property can be postulated (Lucas et al., 1986): external physical attributes, which are descriptors of the external food surface at any one time and which are largely geometric; and internal mechanical characteristics, which govern resistance to the formation of new surfaces (Fig. 1). Presumably, the internal mechanical characteristics of a food are being assessed during the late-closing phase. The slow speed of jaw movement allows time for feedback from mechano- 


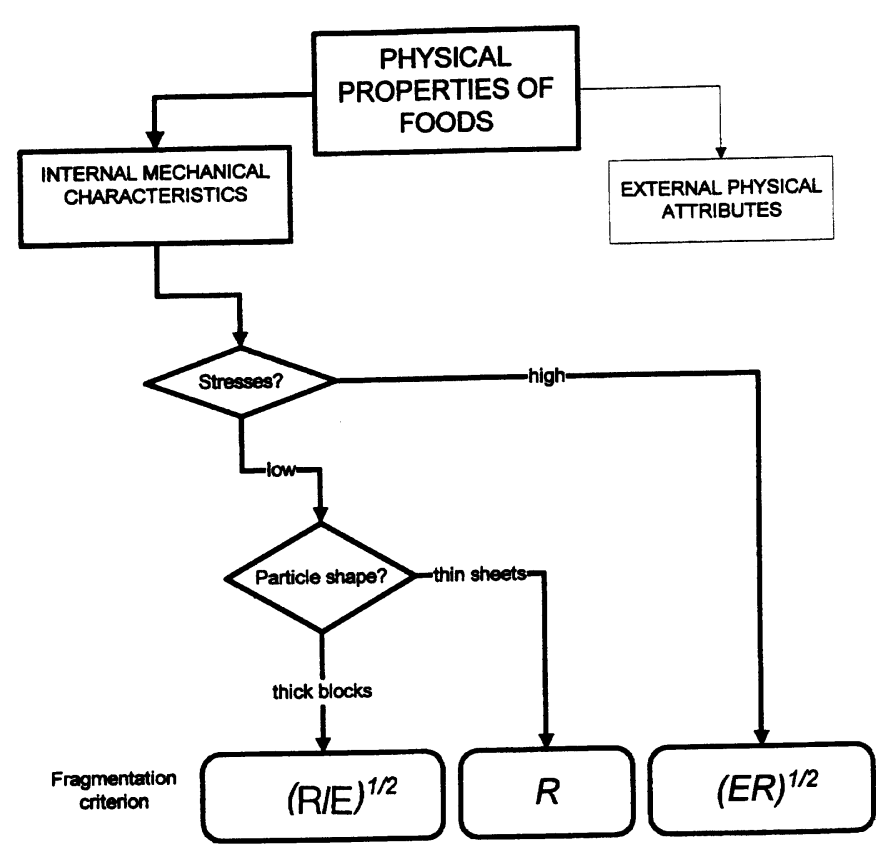

Figure 1. A simple classification of the physical properties of foods and the mechanical indices that are suggested to affect the rate of particle size reduction in mastication and, therefore, the muscular activity needed to achieve this. If stresses are limiting, then (ER $)^{1 / 2}$ is controlling; otherwise it is $(\mathrm{R} / \mathrm{E})^{1 / 2}$. receptors that sense food fracture so that muscular activity in both that chew and subsequent chews can be altered. An analysis of the internal mechanical characteristics involved is given in the "Appendix", where two indices of resistance to particle fragmentation are derived. We have previously found that, for 28 foods, the degree of fragmentation produced by a single bite by the post-canine teeth of humans is highly correlated with one of these indices: $(R / E)^{1 / 2}$, where $R$ is the toughness of each food and $E$ is its modulus of elasticity (Agrawal et al., 1997). Taking this further, to understand the stimulus features influencing the electromyographic (EMG) activity of the closing musculature, we carried out an analysis of the relationship between food properties and muscle activity.

\section{Materials and methods}

\section{Selection of subjects}

Ten adult human volunteers (three female, seven male; age range, 28 to $39 \mathrm{yr}$ ) gave informed consent. Subjects were recruited if they had no history of oral or temporomandibular joint pathology or functional disorders and had intact dental arches (with the exception of one subject, who had lost the lower right first molar). The experimental protocol was approved by the University of Hong Kong's Ethical Committee.

\section{PARMESAN}
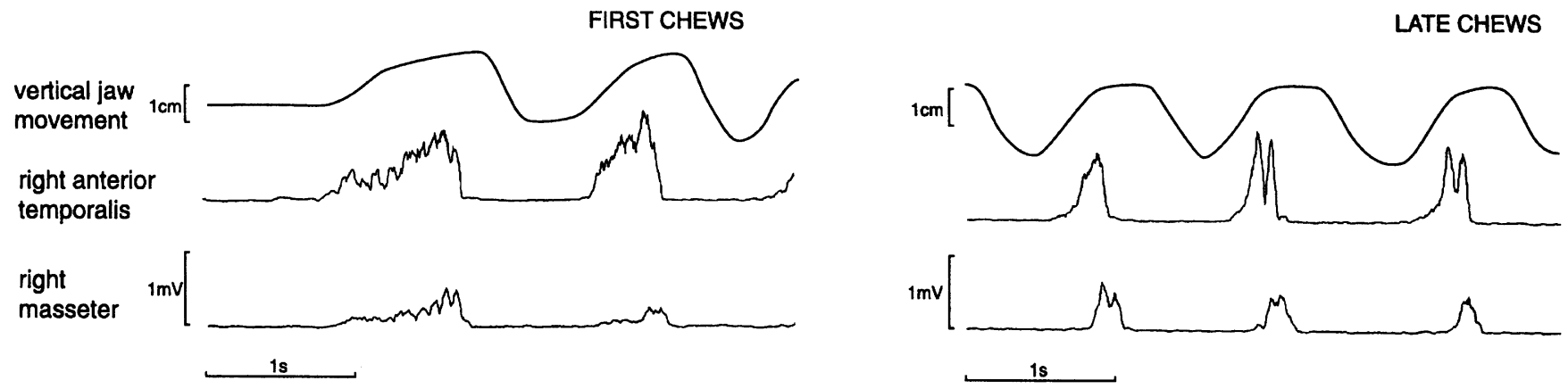

\section{HAZEL NUT}
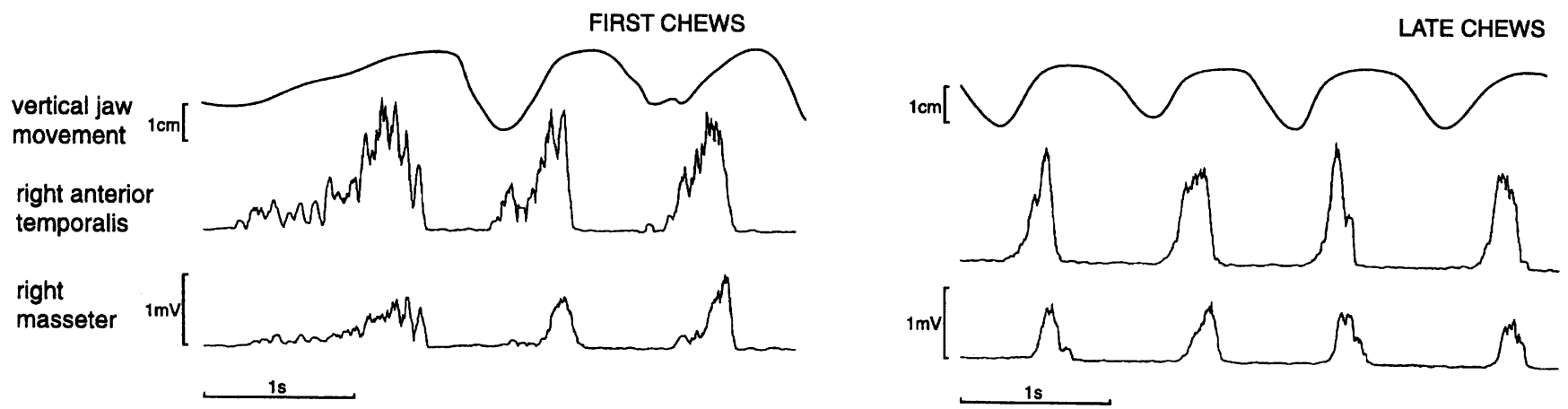

Figure 2. Preliminary experiments illustrating the rectified activity of the right anterior temporalis and right masseter muscles in masticatory sequences on parmesan cheese and hazelnuts. Both muscles were active in closing and while the jaw was moving. The peak in temporalis activity was higher and earlier than for the masseter. In all sequences, EMG activity in this muscle ceased at dental occlusion. 


\section{Selection of foods}

Foods were a subset of the 28 foods used by Agrawal et al. (1997), the number of foods being reduced to keep experimental time to a reasonable length. Foods were obtained from a local supermarket. Cheeses were used not as candidates for regular tests of oral function, or because of the commercial value of dairy research, but because they represented members of a food group with a substantial and even range of properties. As far as we are aware, the mechanical properties of these foods are unaffected when they are chewed.

\section{Mechanical testing of foods}

Testing procedures were those reported by Agrawal et al. (1997). We measured the modulus of elasticity by compressing cylindrical or rectangular specimens in a universal testing machine (Lloyd LRX, Fareham, Hants, UK) at a deformation rate of 5 $\mathrm{mm} \mathrm{min}^{-1}$. Toughness was measured either by means of a pair of scissors or by a wedge test in a portable tester (Darvell et al., 1996); these tests are now standard in biomaterials and in the food industry (Vincent, 1992). All tests were carried out at room temperature. Mean values for these measurements are shown in the Table. All particles except peanuts and hazelnuts were then cut into rectangular blocks measuring $12 \times 13 \times 13 \mathrm{~mm}$. Peanuts and hazelnuts were presented in their natural sizes (hazelnuts, 9 to $10 \mathrm{~mm}$ diameter; peanuts, $19 \mathrm{~mm}$ length, $9 \mathrm{~mm}$ diameter on average).

\section{Selection of muscles}

The anterior temporalis muscles were chosen because, as spindle-rich jaw-closers, they represent one route by which neuromuscular processes ensure that appropriate forces are brought to bear on food particles. The only other easily accessible jaw closers are the masseters. In preliminary experiments, recordings were made from both temporalis and masseter (Fig. 2). During closing, temporalis showed a burst of activity with both a clear onset and offset and with EMG silence during opening. Recordings from the masseter site gave smaller signals with a less clearly defined burst of activity, sometimes contaminated by signals from nearby muscles which are active in opening (e.g., platysma and buccinator). We therefore selected the temporalis signal because it appeared unequivocally related to jaw closure.

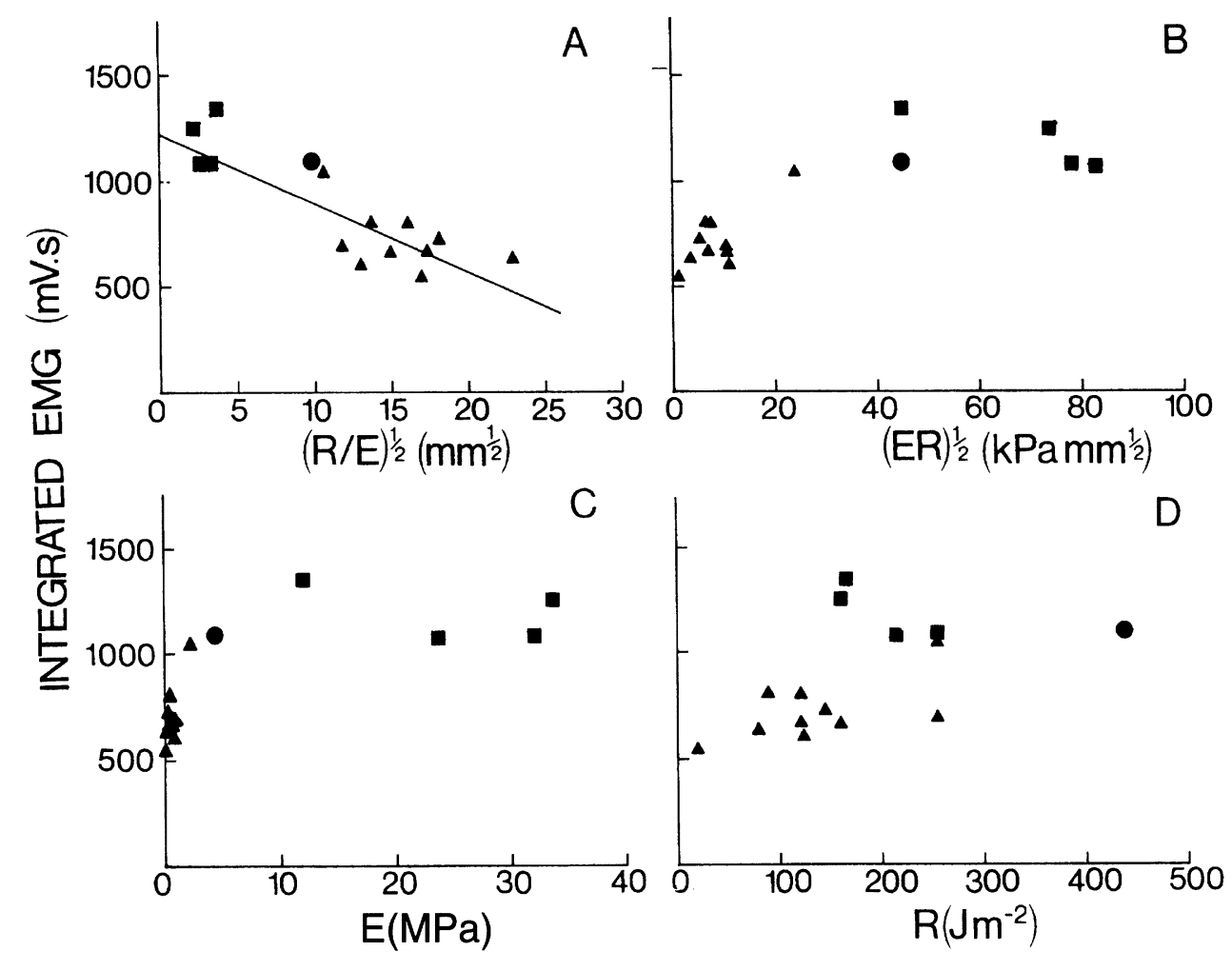

Figure 3. Integrated EMG of the anterior temporalis muscle for all subjects for the average chew within a sequence plotted against the two potential mechanical indices which could be controlling the response of the food: (A) with (R/E) ${ }^{1 / 2}(\mathrm{r}=-0.86 ; \mathrm{p}<0.00001)$; $(\mathrm{B})$ with $(\mathrm{ER})^{1 / 2}(\mathrm{r}=0.82 ; \mathrm{p}<0.001)$; and individual mechanical properties $(C)$ with $E(r=0.72 ; p<0.003)$ and $(D)$ with $R(r=0.59 ; p<0.02)$. Key: cheeses (triangles), nuts (squares), raw carrot (circles).

\section{Recording methods}

Surface EMG from the left and right anterior temporalis muscles during chewing were made by means of disposable $\mathrm{Ag} / \mathrm{AgCl}$ surface electrodes. These were attached after skin preparation with an abrasive gel that lowered impedance (Skin Pure, Nihon Kohden, Tokyo, Japan). The site of electrode placement was established by palpation during jaw clenching. The inside of the electrode was filled with ultrasound transmission gel (Aquasonic, Parker Lab, Orange, NJ, USA). An extra electrode was placed on the left earlobe as a ground. Jaw movements were monitored by means of a Cybermouse (IPC, Freemont, CA, USA), as described by Prinz (1997), so as to identify individual chewing cycles. We recorded swallowing by taping a piezoelectric disc just below the hyoid bone of each subject. The raw EMG signals were amplified (Micro Probe Inc., Clarksburg, MD, USA) at a gain of 3860 . These signals, together with those from jaw movements and swallowing, were then collected through a 10-bit A-to-D converter (Pico Technology Ltd, Hardwick, Cambs,UK) at a sampling rate of $869 \mathrm{~Hz}$ per channel. Soon after the EMG electrodes had been attached, a subject chewed one particle of each food in random order in an habitual manner without head movement until the signal from the piezoelectric discs over the hyoid indicated swallowing. We then analyzed the raw data up to the first swallow by identifying individual chewing cycles from movement traces on the computer screen. For each cycle, the integrated EMG activity of each muscle was then calculated. To avoid variations due to changes in the preferred side of chewing, 


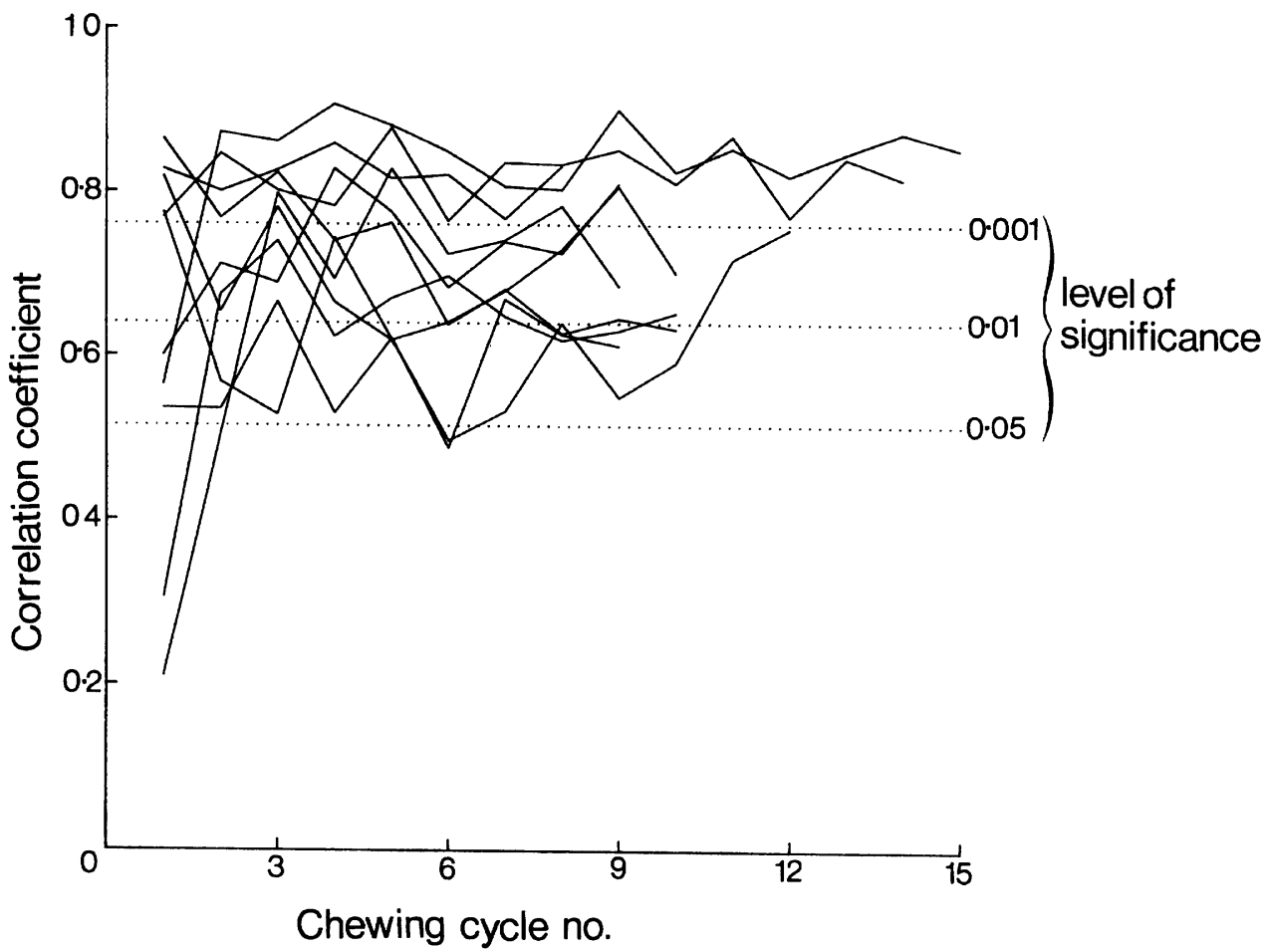

Figure 4. The level of significance of correlation coefficients between integrated EMG activity of the anterior temporalis muscle and $(\mathrm{R} / \mathrm{E})^{1 / 2}$ for each chew for each subject. Correlations were nearly always highly significant and tended to be relatively constant except for the first chew made by two subjects. calculate correlation coefficients between the integrated activity of the muscles in each chew, numbered in sequence, and this mechanical index of the foods. Fig. 4 shows that correlations were generally very high for all but the first chew made by two subjects.

\section{Discussion}

Though it has been commonly supposed that the major factor in the modulation of neuromuscular activity in mastication is the hardness of food (Plesh et al., 1986; Horio and Kawamura, 1989; Ottenhoff et al., 1992; Takada et al., 1994; Peyron et al., 1997), this lacks any theoretical justification. In the dental literature, food "hardness" appears to be used as a synonym for food "material properties". The mechanical tests used to measure it include semiimitative tests involving we combined values for the muscles of each side of the head.

\section{Results}

Fig. 3 shows graphs of the integrated EMG of left and right temporalis muscles combined, averaged for all chews made by all subjects, and plotted against single mechanical properties and the indices derived in the "Appendix". The highest correlation was with the mechanical index $(\mathrm{R} / \mathrm{E})^{1 / 2}$ (Fig. 3A). For comparison, Figs. 3B to 3D show graphs relating integrated muscle activity to the index $(E R)^{1 / 2}$ and to the modulus of elasticity, E, and toughness, $R$, separately. In Fig. 3B, averaged EMG levels when subjects chewed foods with values of $(\mathrm{ER})^{1 / 2}$ between 40 and $80 \mathrm{kPa} \cdot \mathrm{mm}^{1 / 2}$ are seen to be very similar. The least-significant relationships are those with $E$ and $R$, which show clustering of points that give little confidence in a linear relationship. For example, in Fig. 3C, 9 of the cheeses with the lowest moduli of elasticity were chewed with very variable average muscular activity, whereas the other 6 foods, with a variably high modulus of elasticity, were chewed at similar activity levels.

Only analysis of $(R / E)^{1 / 2}$ was investigated further. When the integrated activities of the muscles were averaged over all chews in the masticatory sequence, but separated by subject, there was also a highly significant relationship between bilateral integrated EMG of the anterior temporalis muscle and $(\mathrm{R} / \mathrm{E})^{1 / 2}$ for each subject (between $\mathrm{r}=-0.91$, $p<0.00001$, for the subject showing the best relationship, and $\mathrm{r}=-0.65, \mathrm{p}<0.009$, for the worst). It was also possible to "cusps" driven into food particles (Olthoff et al., 1986; Slagter et al., 1992) or quality control methods used in the food industry (e.g., the Bloom strength of gels [Takada et al., 1994]), both of which betray a lack of interest in the mechanism by which food particles break. Our concern was in isolating the mechanical index that best expresses resistance to food breakdown.

The results presented here indicate that $(\mathrm{R} / \mathrm{E})^{1 / 2}$ probably represents the food property (combinations of individual properties in these mechanical indices can be considered properties in themselves [Ashby, 1989]) which the central nervous system utilizes to modulate the EMG appropriately during the slow-closing phase of a chewing cycle, to ensure efficient reduction of particles. Studies of reflex EMG responses to mechanoreceptor stimulation have shown that sensory feedback may begin to affect EMG activity as early as $20 \mathrm{~ms}$ after substrate contact (van der Bilt et al., 1995). Thus, it is possible to adjust EMG levels within a chew. However, this feedback may also be used to estimate the EMG which will be optimal at the initiation of tooth-food contact in the next cycle in the sequence, to continue reducing the particles further. Our findings show that $(R / E)^{1 / 2}$ to the point at which the first swallow occurred (Fig. 4). Two further features of these correlations are noteworthy: (i) While two subjects apparently "miscalculated" the EMG required for the first bite (the non-significant correlation coefficients shown in Fig. 4), the EMG in their second and subsequent chews was highly correlated with $(R / E)^{1 / 2}$. We was highly correlated with EMG over the chewing cycles up 
predict that if all subjects were tested under conditions preventing their prior knowledge of the food about to be chewed, random EMG "miscalculations" would be found in all first, but not subsequent, chews. (ii) The correlations remained highly significant and relatively constant from the second chew on, in spite of the fact that the substrate was changed by each chew. This indicates that $(\mathrm{R} / \mathrm{E})^{1 / 2}$ may well represent the sensory feedback utilized in the ongoing modulation of the the central pattern generator.

It may be that the strength of the food, which is what many regard as "hardness", defines the material response of the food particle to dental loads. There are two relevant measures of strength: yield strength and fracture strength, where fracture strength < yield strength. Mioche and Peyron (1995) measured the yield stress of industrial materials, correlating this with the psychophysical evaluation of hardness assessed by experimental subjects using a single bite. It has been shown on several occasions, however, that the size of an indentation in a given food or other material, made either by humans (Heath et al., 1982) or by other primates (Lucas et al., 1994; Hill et al., 1995) with their teeth, simply reflects the bite forces that produce them: The definition of hardness is the force that produces unit area of indentation. Thus, if bite force can be sensed, which there is every reason to believe, then Mioche and Peyron's result must logically follow. The fracture strength is not a material property, being strongly influenced by food particle size and rising toward the yield stress as particles get smaller (Atkins and Mai, 1985). Food comminution in mastication quickly generates particle size distributions of several orders of magnitude and, thus, the fracture stress is not constant (Lucas and Luke, 1983, 1984). We suggest that the controlling parameter for food breakdown and EMG activation is the energy balance within the particle, which, for a homogeneous material, is a function of toughness and the modulus of elasticity (Atkins and Mai, 1985), and that EMG activation patterns reflect the sensing of the rate of breakdown which this combination of properties controls.

\section{Acknowledgments}

We thank L.Y.L. Siu for technical support, the Committee for Research and Conference Grants of the University of Hong Kong, and volunteers who participated.

\section{References}

Agrawal KR, Lucas PW, Prinz JF, Bruce IC (1997). Mechanical properties of foods responsible for resisting food breakdown in the human mouth. Arch Oral Biol 42:1-9.

Ashby MF (1989). On the engineering properties of materials. Acta Metall 37:1272-1293.

Ashby MF (1992). Materials selection in mechanical design. Oxford: Pergamon Press.

Ashby MF (1993). Criteria for selecting the components of composites. Acta Metall et Mater 41:1313-1335.

Atkins AG (1994). Scale effects in engineering fractures. Eng Failure Anal 1:201-214.

Atkins AG, Mai Y-W (1985). Elastic and plastic fracture. Chichester: Ellis Horwood.

Table. Foods used in this study and their mean mechanical properties

\begin{tabular}{lcc} 
Food & $\begin{array}{c}\text { Modulus of } \\
\text { Elasticity }(\mathrm{MPa})\end{array}$ & $\begin{array}{c}\text { Toughness } \\
\left(\mathrm{Jm}^{-2}\right)\end{array}$ \\
\hline
\end{tabular}

Cheeses:

Apericube processed cheese

(Bel, France)

0.07

0.85

0.29

0.47

0.47

0.41

0.71

0.89

0.15

2.26

Parmesan

Nuts:

Brazil nut (Eden's, Australia)

Hazel nut (Eden's, Australia)

Macadamia nut (Eden's, Australia)

Peanut (roasted salted)

(Planter's, Nabisco, Singapore)

23.9

Raw vegetable: carrot

4.57

33.8

12.2

32.2

Darvell BW, Lee PK, Yuen TD, Lucas PW (1996). A portable toughness tester for biological materials. Meas Sci Technol 7:954-962.

Heath MR (1982). The effect of maximum biting force and bone loss on masticatory function and dietary selection of the elderly. Int Dent J 32:345-356.

Hiiemae KM, Crompton AW (1985). Mastication, food transport, and swallowing. In: Functional vertebrate morphology. Hildebrand M, Bramble DM, Liem KF, Wake DB, editors. Cambridge: Belknap Press of Harvard University, pp. 262-290.

Hiiemae KM, Hayenga SM, Reese A (1995). Patterns of tongue and jaw movement in a cinefluorographic study of feeding in the macaque. Arch Oral Biol 40:229-246.

Hill DA, Lucas PW, Cheng PY (1995). Bite forces used by Japanese macaques (Macaca fuscata yakui) on Yakushima Island, Japan to open aphid-induced galls on Distylium racemosum (Hamamelidaceae). J Zool 237:57-63.

Hoaglund RG, Rosenfield AR, Hahn GT (1972). Mechanisms of fast fracture and arrest in steels. Metall Trans 3:123-136.

Horio T, Kawamura Y (1989). Effects of texture of food on chewing patterns in the human subject. J Oral Rehabil 16:177-1983.

Kendall K (1978). The impossibility of comminuting small particles by compression. Nature 272:710-711.

Lawn BR, Wilshaw T (1975). Indentation fracture: principles and applications. J Mater Sci 10:1049-1081.

Lucas PW, Luke DA (1983). Methods for analysing the breakdown of food during human mastication. Arch Oral Biol 28:813-819. 
Lucas PW, Luke DA (1984). Optimal mouthful for food comminution in human mastication. Arch Oral Biol 29:205-210.

Lucas PW, Corlett RT, Luke DA (1986). New approach to postcanine tooth size applied to Plio-pleistocene hominids. In: Primate evolution. Else JG, Lee PC, editors. Cambridge: Cambridge University Press, pp. 191-201.

Lucas PW, Peters CR, Arrandale SR (1994). Seed-breaking forces exerted by orangutans with their teeth in captivity and a new technique for estimating forces produced in the wild. Am J Phys Anthropol 94:365-378.

Lund JP (1976). Evidence for a central neural pattern generator regulating the chewing cycle. In: Mastication. Anderson DJ, Matthews B, editors. Bristol: Wright, pp. 204-212.

Lund JP, Widmer CG (1989). An evaluation of the use of surface electromyography in the diagnosis, documentation, and treatment of dental patients. J Craniomandib Disord Fac Oral Pain 3:125-137.

Luschei ES, Goldberg LJ (1981). Neural mechanisms of mandibular control: mastication and voluntary biting. In: Handbook of physiology-Section I: The nervous system. Vol. II. Motor control, Part II. Brookhart JM, Mountcastle VB, Brooks VB, Geiger SR, editors. Bethesda: American Physiological Society, pp. 1237-1273.

Mioche L, Peyron MA (1995). Bite force displayed during assessment of hardness in various texture contexts. Arch Oral Biol 40:415-423.

Olthoff LW, van der Bilt A, de Boer A, Bosman F (1986). Comparison of force-deformation characteristics of

\section{Appendix}

The behavior of solid particles as a response to load can be divided into an early phase, in which the disturbance to equilibrium is counteracted by an elastic deformation-i.e., a temporary change in shape-and a later phase, when the disturbance has gone as far as to produce a crack that is propagating through the particle. In materials with relatively simple elastic behaviors and which crack during chewing, such as the food materials that we used in our experiments, the early phase can be characterized by the modulus of elasticity of the material of which the particle is made, while the latter can be described by its toughness. The modulus of elasticity is the ratio of the stress to the strain in the linear portion of the stress-strain curve, while toughness is the energy absorbed by the formation of a unit area of crack. At the junction between the two phases of material behavior lies the point of crack initiation, which can be described by a breaking (or fracture) stress. It is known in materials science that neither the modulus of elasticity nor toughness is alone capable of describing resistance to particle fragmentation. Elastic behavior has nothing intrinsically to do with fracture. In a composite like a food material, the modulus is determined by that of the artificial and several natural foods for chewing experiments. J Texture Stud 17:275-289.

Ottenhoff FA, van der Bilt A, van der Glas HW, Bosman F (1992). Control of elevator muscle activity during simulated activity with varying food resistance in humans. J Neurophysiol 68:933-944.

Peyron MA, Maskawi K, Woda A, Tanguay R, Lund JP (1997). Effects of food texture and sample thickness on mandibular movement and hardness assessment during biting in man. J Dent Res 76:789-795.

Plesh O, Bishop B, McCall W (1986). Effect of gum hardness on chewing pattern. Exp Neurol 92:502-512.

Prinz JF (1997). The Cybermouse: a simple method of describing the trajectory of the human mandible in three dimensions. $J$ Biomech 30:643-645.

Slagter AP, van der Glas HW, Bosman F, Olthoff LW (1992). Force-deformation properties of artificial and natural foods for testing chewing efficiency. J Prosthet Dent 68:790-799.

Takada K, Miyawaki S, Tatsuda M (1994). The effects of food consistency on jaw movement and posterior temporalis and inferior orbicularis oris in children. Arch Oral Biol 39:793-805.

van der Bilt A, Weijnen FG, Ottenhoff FA, van der Glas HW, Bosman F (1995). The role of sensory information in the control of rhythmic open-close movements in humans. $J$ Dent Res 74:1658-1664.

Vincent JFV (1992). Biomechanics. Materials: a practical approach. Oxford: IRL. component parts of the composite, which set bounds. Unlike the modulus of elasticity, toughness has no structural bounds and depends on the expression of mechanisms in which components can act synergistically: Composites generally have a toughness much greater than that of their component parts. Yet toughness alone is also inadequate to describe resistance to crack propagation, because it does not take into account how the differing stiffnesses of the material on either side of the crack can deform to obstruct crack growth. As an example of this, bone and rubber have rather similar toughnesses, around $1000 \mathrm{~J} \mathrm{~m}^{-2}$. However, the former shatters under a compressive load, whereas the latter will not break at all. Rubber absorbs the energy of loading, elastically blunting any cracks that form. A ceramic composite such as dentin has a modulus of elasticity similar to that of many woods (around 10 to $15 \mathrm{GPa}$ ), yet dentin can shatter, while woods do not. It may be argued that this discussion is missing the point, and that it is breaking stress (or breaking strain) which controls the potential to shatter. Reality is the opposite: In materials that suffer elastic fracture, the magnitude of the breaking stress is a function of toughness and is not a fundamental property at all. Clear evidence of this is the dependence of breaking stress on 
particle (or specimen) size (Atkins, 1994).

It would seem reasonable from the above to suppose, for the food materials that we have tested, that a combination of the modulus of elasticity and toughness would serve as an index of the resistance to particle breakdown. This appendix demonstrates this according to methods developed by Ashby $(1989,1992,1993)$, who has derived a set of general mechanical indices that describe the material responses of solids to being loaded. In most instances, one need specify only the general form of loading to decide which index describes the response of the solid in question, because terms in the equations that describe the geometry of the contact can be separated from terms that contain the mechanical properties of that solid (Ashby, 1992). Under dental loads, two of Ashby's (1989) indices seem logically appropriate, with the degree of fragmentation being limited either by the displacement available or by the stress that can be imposed. The distinction is quite critical. Fig. A.1 illustrates this in a dental context, where a post-canine tooth makes a hypothetical contact in the later part of the closing phase of a chewing cycle with a homogeneous food particle with a modulus of elasticity, E, and toughness, R. Cracks that initiate in that particle could form at or away from the tooth-food contact interface and grow quickly or slowly. If they grow slowly, then the final degree of fragmentation will depend on how many cracks have completed their path and separated fragments. The displacement-limited index is illustrated with respect to Fig. A.1A, where a food particle is shown behaving like a beam. Any type of loading could be envisaged, however, and the shape of the contact surface is not critical.

Before the beam-like food particle in Fig. A.1 cracks, its deflection under a force $\mathrm{F}$ can be described by

$$
\delta=3 F l^{3} / 4 E b t^{3}
$$

with each symbol shown in Fig. A.1B. At the initiation of cracking (Fig. A1C), the maximum stress (on the noncontact surface opposite the cusp tip) will be

$$
\sigma_{F}=3 F l / 2 b t^{2}
$$

Substituting for the load and separating the geometry from the material properties, we have

$$
\sigma_{F} / E=6 \delta \mathrm{t} / 1^{2}
$$

Thus, if the potential for initiating a crack within food particles is limited by a particular deflection, $\delta$, this varies as $\sigma_{\mathrm{F}} / \mathrm{E}$ of the food in question. As stated above, $\sigma_{\mathrm{F}}$ is dependent on particle size, which is hardly appropriate for an analysis involving comminution, and is insufficient for our analysis. Particle fragmentation during mastication can be understood only in the context of crack propagation. This is the field of fracture mechanics where the intensification of the stress, $\mathrm{K}_{\mathrm{IC}}$ in a particle containing a crack of length a is given by the critical stress intensity factor

$$
K_{I C}=\sigma_{F}(\pi a)^{1 / 2}
$$

Dividing Eq. (4) by E gives

$$
K_{I C} / E=\left(\sigma_{F} / E\right) \cdot(\pi a)^{1 / 2}
$$

and since for the relatively simple material behavior we are assuming, $R \approx K_{I C}{ }^{2} / E$, then Eq. (5) becomes

$$
(R / E)^{1 / 2}=\left(\sigma_{F} / E\right) \cdot(\pi a)^{1 / 2} .
$$

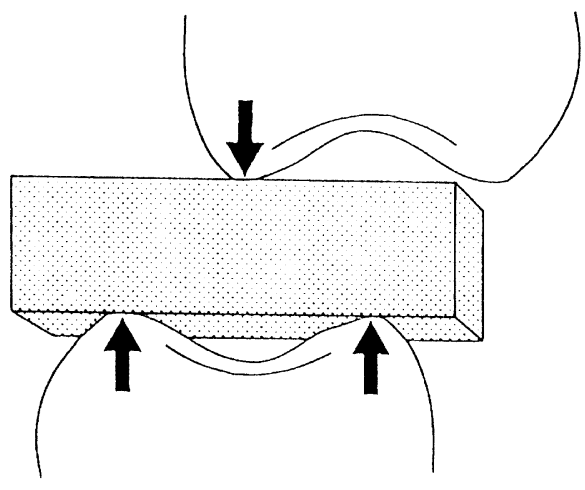

A

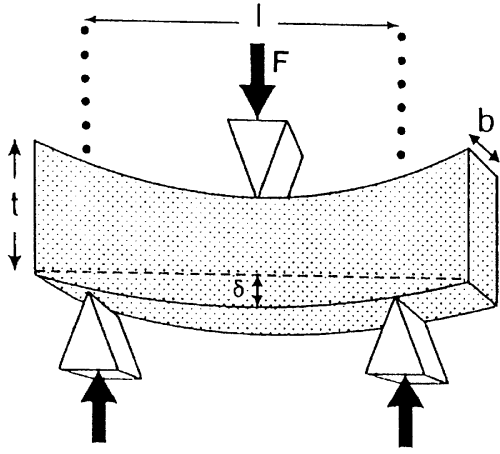

B

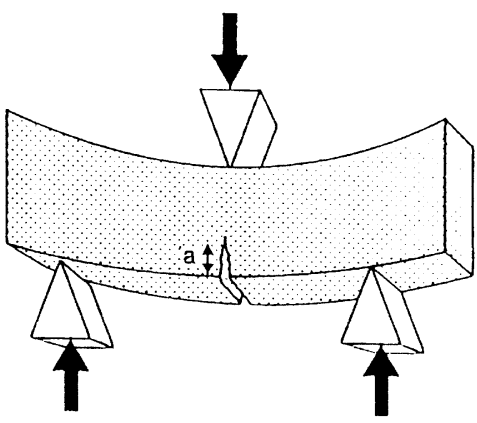

C

Figure A.1. The general form of loading of food particles by the human post-canine teeth in the later part of the closing phase of a chewing cycle. (A) A beam-like food particle (shaded) is shown loaded by alternating upper and lower cusps. In (B), this loading is idealized to suggest that the food particle, of length between cuspal supports, 1 , breadth, $b$, and thickness, $t$, is deforming under three-point bending. The greatest deflection, $\delta$, is under the central cusp. The large arrows indicate the direction of the force with magnitude $F$. In (C), a crack of length a has formed on the non-contact surface. The ability of the teeth to run this crack through the particle will depend on the distance available until tooth-tooth contact, i.e., this is displacement-limited fragmentation. 


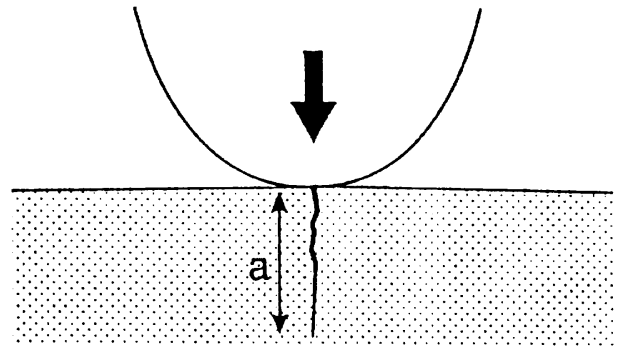

A

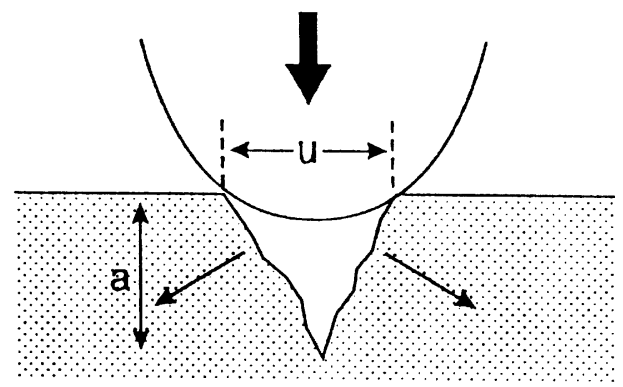

B

Figure A.2. In (A), instead of bending as in Fig. A.1, a crack of length $a$ has formed by indentation of a tooth cusp. If this propagates rapidly, as indicated, then further displacement of the cusp is not required to run this crack. This is stress-limited fragmentation. In (B), the crack that was formed in (A) has arrested and is being driven by the cusp as though the latter were a wedge. This forces the two halves of the particle apart, to get fragmentation. This is again displacement-limited fragmentation, similar to Fig. A.1.

fragments that subsequently form, then final fragmentation will be limited by the small displacement remaining until the teeth occlude. The appropriate index then is the displacement-limited fragmentation index, $(\mathrm{R} / \mathrm{E})^{1 / 2}$.

In Fig. A.2A, a crack (the median vent of Lawn and Wilshaw, 1975) is forming due to the indentation of a cusp into the food surface. If this propagates rapidly, then the stress-limited index, the critical stress intensity factor $\mathrm{K}_{\mathrm{IC}}$, or $(\mathrm{ER})^{1 / 2}$ in our terms, applies, and Eq. (4) is approximately correct. If it arrests, then it is necessary for the tooth to wedge this crack apart (Fig. A.2B), when the amount of fragmentation produced will again be displacement-limited:

$(R / E)^{1 / 2}=0.866 u w^{1.5} / a^{2}\left(1+0.64 w / a^{2}\right)$ where $w=0.5 b$ and $u$ is the width of contact of the cusp at the point at which the crack of length a starts to grow (Fig. A.2B) (Hoaglund et al., 1972). As food particles get smaller or if sheetlike particles are being chewed, cracking under the pressure of the teeth becomes suppressed (Kendall, 1978). However, particles can still be fragmented by cusps passing through these particles, physically dividing them. The displacementlimited index no longer applies, though, because these particles are not capable of storing much strain energy. Instead, the work done by the teeth in breaking down these particles becomes directly transferred into work of fracture. This work per area of crack is some multiple of the toughness, $R$, of the food, the exact value depending on the form of the contact. These various relationships are summarized in Fig. 1. 